\title{
Risk of schizophrenia increased with increasing paternal age
}

Malaspina D, Harlap S, Fennig S, et al. Advancing paternal age and the risk of schizophrenia. Arch Gen Psychiatry 2001

Apr;58:361-7.

\section{QUESTION: Is advanced paternal age associated with an increased risk of schizophrenia in offspring?}

\section{Design}

Birth cohort study with follow up of offspring to $\geqslant 21$ years of age.

\section{Setting}

Jerusalem, Israel.

\section{Participants}

87907 offspring who were born between 1964 and 1976 to parents in a defined geographic area of Jerusalem (Jerusalem Perinatal Study). Exclusion criteria were unknown paternal or maternal age, unknown year of parents' marriage, or if the father's age was shown to be $>10$ years younger than the mother's.

\section{Assessment of risk factors}

Parents' age at birth of offspring, sex, ethnicity, education, and duration of marriage were obtained from birth certificates, hospital and clinic records, and interviews with mothers that were compiled into a research database that was linked to a national registry of psychiatric disorders.

\section{Main outcome measures}

Schizophrenia, schizo-affective, schizotypal, and delusional disorders.

\section{Main results}

At 21 and up to 34 years of age, 335 and 658 offspring, respectively, were diagnosed with schizophrenia related non-affective and schizo-affective psychoses. Univariate analysis at 21 years of age showed that the risk of schizophrenia increased with increasing age of both the father $(\mathrm{p}<0.001)$ and mother $(\mathrm{p}<0.01)$ at offspring's birth. Multivariate analysis with adjustment for the age of the other parent showed that only paternal age was associated with increased risk of schizophrenia up to 34 years of age (table). Treating paternal age as a continuous variable, each decade increase in paternal age multiplied the risk of schizophrenia in his offspring by 1.56 (95\% CI, 1.36 to 1.78). After controlling for maternal age and other confounders (sex, ethnicity, education, and duration of marriage), paternal age remained a significant predictor of the schizophrenia diagnoses.

\section{Conclusion}

After controlling for maternal age, duration of marriage, sex of offspring, ethnicity, and education, advanced paternal age was associated with increased risk of schizophrenia in offspring.

Relative risk of schizophrenia in offspring according to age of parent

\begin{tabular}{lll} 
Age $(\mathbf{y})^{*}$ & $\begin{array}{l}\text { Maternal relative risk }(95 \% \\
\text { Cl) } \dagger\end{array}$ & Paternal relative risk $(\mathrm{Cl}) \dagger$ \\
\hline $25-29$ & $1.01(0.81$ to 1.26$)$ & $1.14(0.84$ to 1.53$)$ \\
\hline $30-34$ & $1.10(0.84$ to 1.44$)$ & $1.42(1.03$ to 1.96$)$ \\
\hline $35-39$ & $1.18(0.84$ to 1.67$)$ & $1.64(1.13$ to 2.38$)$ \\
\hline $40-44$ & $1.08(0.65$ to 1.80$)$ & $1.73(1.11$ to 2.70$)$ \\
\hline $45-49$ & - & $2.02(1.17$ to 3.51$)$ \\
\hline $50-54$ & - & $2.96(1.60$ to 5.47$)$ \\
\hline
\end{tabular}

*Participants 20-24 years of age were used as the reference group.

†Relative risk was adjusted for age of other parent.

\section{COMMENTARY}

The study by Malaspina et al tries to answer 2 questions. Firstly, it attempts to establish whether advancing of paternal, but not maternal age, leads to increased incidence of schizophrenia, schizotypal, and delusional disorders. In this respect it confirms the findings of several older and smaller studies. To my knowledge it is the first study to establish a direct and linear correlation between advancing paternal age and risk of schizophrenia. It uses a larger sample and (arguably) more powerful combination of a large birth cohort and national psychiatric registry. Known methodological drawbacks exist with such an approach, although for the purpose of this study it is less likely that there will be a systematic bias. One drawback is that the time span of the study encompasses 3 different editions of $\operatorname{ICD}(8,9$, and 10$)$ with different criteria and possible conceptual changes. Another drawback is the possible loss to follow up of younger parents and their children (eg, through migration), which was examined by the authors.

The second question -"What causes such correlation?"-is answered more speculatively. Indeed, it is possible that new mutations of the paternal germinative cells may explain the increased incidence of schizophrenia. In my opinion, the design of the study cannot answer this question. Other factors may affect the correlation between paternal age and incidence of schizophrenia (eg, higher birth order).

From a practical point of view, interpreting the study and translating the results to patients, their families, and the general public must be done very carefully, giving consideration to a variety of issues, including ethical ones. We remember the enormous guilt brought by the concept of the "schizophrenogenic mother" to sufferers and families alike. It is also important that this study be replicated in other geographical and cultural settings.

In conclusion, this very important study approaches an old question about genetic aetiology from an entirely different vantage point. It raises a number of questions with scientific, preventive, ethical, and moral implications. It opens a door and calls for a variety of further studies. It is a step toward a better understanding of a complex and disabling condition.

Roumen Milev, MD, PhD, FRCPC, MRCPsych Mental Health Clinic; Regina, Saskatchewan, Canada

1 Hultman CM, Sparen P, Takei N, et al. Prenatal and perinatal risk factors for schizophrenia, affective psychosis, and reactive psychosis of early onset: case-control study. BMJ 1999;318:421-6.

Sources of funding: National Institutes of Health, Bethesda, MD and the $G$ Harold and Leila Y Mathers Charitable Foundation, Mount Kisco, New York.

For correspondence: Dr D Malaspina, New York State Psychiatric Institute, 1051 Riverside Drive, New York, NY 10032, USA. Fax +1212543 6176. 